\title{
Analysis of Drought Characteristics in Xilingol Grassland of Northern China Based on SPEI and Its Impact on Vegetation
}

\author{
Siqin Tong, ${ }^{1,2,3}$ Yuhai Bao, ${ }^{2,3}$ Rigele Te, ${ }^{2,3}$ Qiyun $\mathrm{Ma},{ }^{1} \mathrm{Si} \mathrm{Ha},{ }^{1}$ and A. Lusi ${ }^{1}$ \\ ${ }^{1}$ School of Environment, Northeast Normal University, Changchun 130117, China \\ ${ }^{2}$ College of Geographical Science, Inner Mongolia Normal University, Hohhot 010022, China \\ ${ }^{3}$ Inner Mongolia Key Laboratory of Remote Sensing and Geographic Information System, Hohhot 010022, China
}

Correspondence should be addressed to Yuhai Bao; baoyuhai@imnu.edu.cn

Received 20 September 2016; Revised 11 November 2016; Accepted 7 December 2016; Published 18 January 2017

Academic Editor: Hasi Bagan

Copyright (C) 2017 Siqin Tong et al. This is an open access article distributed under the Creative Commons Attribution License, which permits unrestricted use, distribution, and reproduction in any medium, provided the original work is properly cited.

\begin{abstract}
This research is based on the standardized precipitation evapotranspiration index (SPEI) and normalized difference vegetation index (NDVI) which represent the drought and vegetation condition on land. Take the linear regression method and Pearson correlation analysis to study the spatial and temporal evolution of SPEI and NDVI and the drought effect on vegetation. The results show that (1) during 1961-2015, SPEI values at different time scales showed a downward trend; SPEI-12 has a mutation in 1997 and the SPEI value significantly decreased after this year. (2) During 2000-2015, the annual growing season SPEI has an obvious upward trend in time and the apparent wetting spatially. (3) In the recent 16 years, the growing season NDVI showed an upward trend and more than $80 \%$ of the total area's vegetation increased in Xilingol. (4) Vegetation coverage in Xilingol grew better in humid years and opposite in arid years. SPEI and NDVI had a significant positive correlation; $98 \%$ of the region showed positive correlation, indicating that meteorological drought affects vegetation growth more in arid and semiarid region. (5) The effect of drought on vegetation has lag effect, and the responses of different grassland types to different scales of drought were different.
\end{abstract}

\section{Introduction}

Grassland is one of the widely distributed ecosystems on the earth; it plays an important role in global carbon cycle and climate system [1] and also has vital function on animal husbandry production and socioeconomic development [2]. However, grassland is one of the most vulnerable ecosystems as well, which is seriously affected by climate changes [1]. Global climate change, whether it is warming or cooling, and greenhouse gas concentration change will lead to changes on spatial-temporal distribution pattern of climate factors, such as sunlight, temperature, and precipitation, which are the indispensable factor in the process of vegetation growth [3]; moreover these changes will be exacerbated the formation of disastrous elements [4] and then will have a profound impact on changes of vegetation growth, productivity, and accompanying socioeconomic progress $[5,6]$.

Drought is one of the most serious natural disasters in the world. It has the characteristics of high frequency, wide range, and long duration [7]. It also has great influence on agriculture, water resources, natural ecosystem, and society, and then it brings huge economic losses, famine, epidemic, land degradation, and other negative effects [8]. Because of the global climate warming, drought occurs frequently and there is a clear upward trend. It has a direct impact on the development of agriculture and animal husbandry in Mongolia steppe [9] and accelerates the desertification and causes severe sand storm [10]. Therefore, drought assessment and monitoring are essential to reducing the losses and ensuring the safety of human being and property. Although the drought phenomenon is very complex, it can still be characterized by drought index, such as the Standardized Precipitation Index (SPI), Palmer Drought Severity Index (PDSI), Surface Water Supply Index (SWSI), and Effective Drought Index (EDI) [11]. The drought index can be used to quantify the intensity and duration of drought, as well as the occurrence of spatial extent [12]. In this study, the standardized precipitation evapotranspiration index (SPEI) 


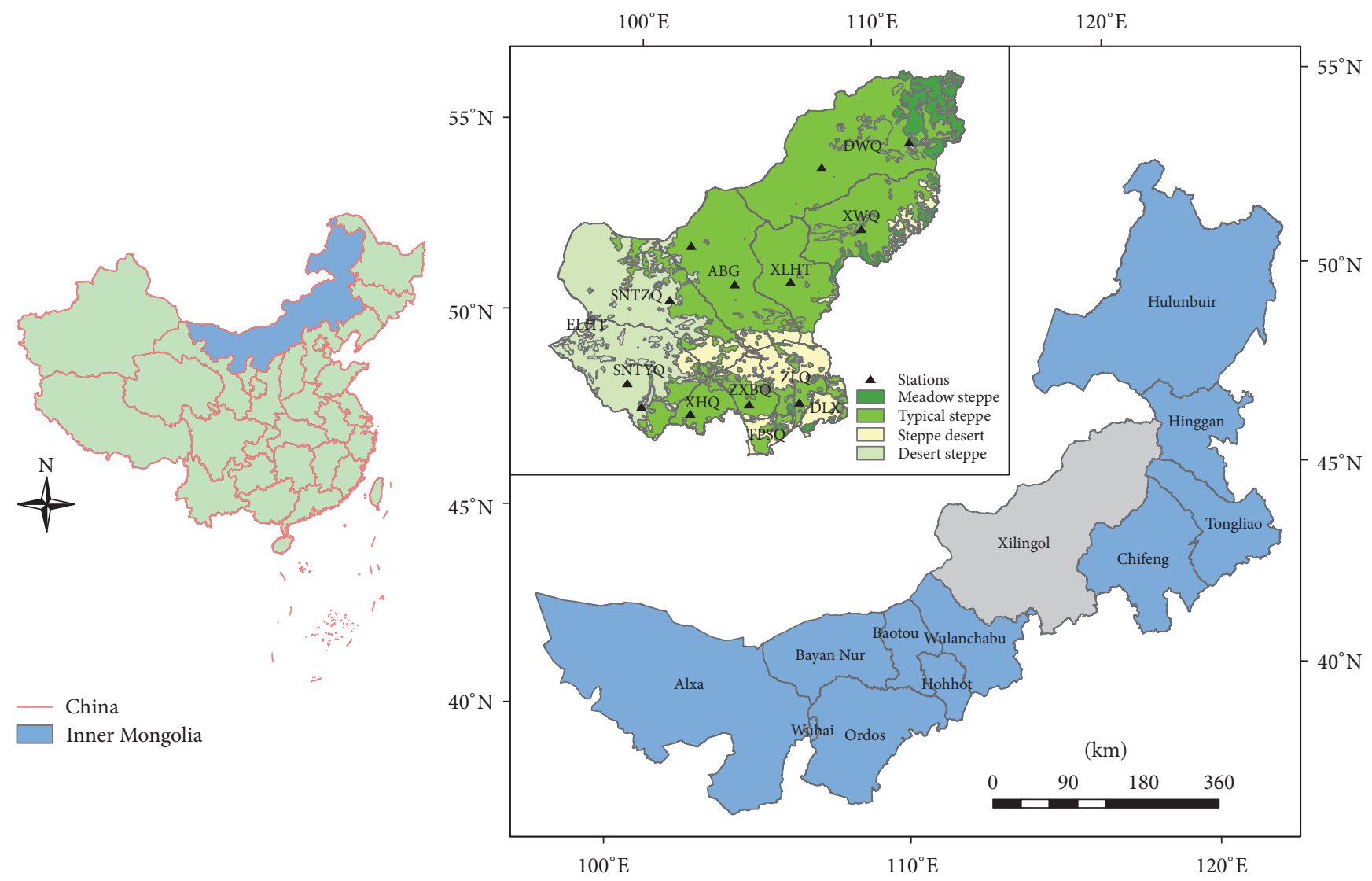

FIGURE 1: Location of study area, spatial distribution of meteorological stations, and grassland types of Xilingol.

was selected to analyze the dynamics of drought. It is widely used to analyze drought in various fields, because it not only considers the role of precipitation and evapotranspiration in drought causes, but also retained the sensitivity of SPI and PDSI index to temperature and precipitation, and it also has advantage of multiscale and multispace [13]. The frequent occurrence of drought and long duration hinder the normal green up and growth of grassland, cause the decrease of productivity in grassland, and pose a great threat to the sustainable development of the economy of animal husbandry. Therefore, it is of great significance to monitor and reveal the impact of drought to vegetation and to study the relationship between climate change and terrestrial ecosystem. In recent years, a great number of researchers have studied the relationship between vegetation and drought; however, the current study mainly concentrated on the relation between vegetation and single climate factor [14-17]. And this is not able to reflect the effect of climate change on vegetation [7]. On the other hand, most studies focused on a watershed analysis and have less attention on the correlation analysis of vegetation and drought, especially the drought impact on vegetation in Xilingol grassland which has not been reported yet.

Xilingol grassland locates in the north of China, and it is one of the three major natural grasslands of China and the typical temperate grassland of Eurasia, as well as the most complete preservation of word's temperate grassland in the
Central Plains plants. However, due to the typical continental climate and fragile ecological system, Xilingol grassland is vulnerable to global climate change and human activities. Studies have shown that the degradation of grassland in Xilingol reached to $64 \%$ of total area because of the global climate change and expansion of usage and intensity in grassland types [18]. The environmental problems such as sand storm, drought, and desertification became progressively worse [19], bringing adverse effect on local animal husbandry production and ecological environment [20]. Therefore, we make use of the MODIS NDVI and meteorological data to monitor the dynamic of vegetation and drought in Xilingol grassland and discuss the drought impact on vegetation at different time scales. This will have an important theoretical and practical significance to the spatial-temporal change pattern of vegetation in grassland, rational use of limited grassland resources, effective management and forecast the impact of climate change on grassland ecosystem, and risk assessment and early warning on the natural disasters in grassland pasturing area [21].

\section{Data and Method}

2.1. Study Area. Xilingol grassland $\left(41^{\circ} 35^{\prime} \sim 46^{\circ} 46^{\prime} \mathrm{N}, 111^{\circ} 09^{\prime}\right.$ $\left.\sim 119^{\circ} 58^{\prime} \mathrm{E}\right)$ is located in northern China, central Inner Mongolia (Figure 1); it is the largest natural pasture and animal husbandry base in China and belongs to the arid and semiarid 
continental climate. The annual average temperature ranges from 0 to $3^{\circ} \mathrm{C}$ and it is gradually increasing from east to west, While the precipitation gradually decreases from east to west and ranges from 300 to $380 \mathrm{~mm}$. There is distributed meadow steppe, typical steppe, steppe desert and desert steppe, and continuous steppe in the spatial grassland from the northeast to the southeast. The south of Xilingol has a Hunshandake sandy land and farming-pastoral zone (DLX and TPSQ).

2.2. Data Sources and Preprocessing. The usage of NDVI dataset is MODIS NDVI, which can be downloaded from the NASA Goddard Space Flight Center (https://ladsweb.nascom.nasa.gov/) for free. The original MOD13A2 data has a spatial resolution of 1000 meters with 16-day composite. The monthly NDVI is generated with the Maximum Value Composite (MVC) method. MVC chooses the highest value of each pixel from the multitemporal data to represent the current NDVI value [22]. The annual growing season NDVI is defined as the average of NDVI values from April to October of each calendar year, because most vegetation in Xilingol almost stops growing or is covered with snow in winter.

The climate data used in this study was acquired from the China Meteorological Data Sharing Service System (http://data.cma.cn/), including monthly mean air temperature and monthly precipitation for the period 1961-2015, with the 15 meteorological stations that cover the whole area of Xilingol. And these two datasets are used to calculate the SPEI drought index.

The grassland type's data were extracted from the 1: 1000000 vector vegetation map of Inner Mongolia. Xilingol has four different grassland types and its distribution is shown in Figure 1 [23].

2.3. Standardized Precipitation Evapotranspiration Index (SPEI). It is a kind of multitime scale index for drought, and it uses the difference between precipitation and evapotranspiration to characterize the intensity of drought in a certain region. The main steps for calculating SPEI are shown as follows [13]:

(1) Potential Evapotranspiration (PET) is estimated by the Thornthwaite method [24].

$$
\operatorname{PET}=16 K\left(\frac{10 T_{i}}{I}\right)^{m}
$$

where $T_{i}\left({ }^{\circ} \mathrm{C}\right)$ is the monthly mean temperature; $I$ is the yearly heat index, $I=\sum_{i=1}^{12} I_{i}=\sum_{i=1}^{12}\left(T_{i} / 5\right)^{1.514} ; i$ is the month; $m$ is a constant value, $m=6.75 E^{-7} I^{3}-$ $7.71 E^{-5} I^{2}+1.79 E^{-2} I+0.492 ; E$ is exponential function; $K$ is correction factor.

(2) Calculate water balance, which is the difference between precipitation $(P)$ and PET, as follows:

$$
D_{i}=P_{i}-\mathrm{PET}_{i}
$$

where $D$ is water balance; $P(\mathrm{~mm})$ is precipitation; PET $(\mathrm{mm})$ is potential evapotranspiration.
(3) Water balance at different time scales is aggregated.

$$
D_{n}^{k}=\sum_{i=0}^{k-1}\left(P_{n-1}-\operatorname{PET}_{n-i}\right), \quad n \geq k
$$

where $k$ (month) is the scale of interest; $n$ is the calculation month; $D_{n}^{k}$ is the accumulated water balance.

(4) The water balance is normalized into a log-logistic probability distribution to calculate the SPEI index series.

$$
f(x)=\frac{\beta}{\alpha}\left(\frac{x-\gamma}{\alpha}\right)^{\beta-1}\left[1+\left(\frac{x-\gamma}{a}\right)\right]^{-2},
$$

where $\alpha, \beta$, and $\gamma$ are the scale, shape, and origin parameters, respectively. The probability distribution function of the $D$ series is given by

$$
F(x)=\left[1+\left(\frac{x-\gamma}{\alpha}\right)^{\beta}\right]^{-1} .
$$

(5) With $F(x)$ the SPEI can easily be obtained as the standardized value of $F(x)$

$$
\mathrm{SPEI}=W-\frac{C_{0}+C_{1} W+C_{2} W^{2}}{1+d_{0} W+d_{2} W^{2}+d_{3} W^{3}},
$$

where $W=\sqrt{-2 \ln (P)}$; if $P \leq 0.5, P=1-F(x)$; if $P>0.5, P=1-P$. The constants are $C_{0}=2.515517$, $C_{1}=0.802853, C_{2}=0.010328, d_{1}=1.432788, d_{2}=$ 0.189269 , and $d_{3}=0.001308$. And linear regression method and Pearson correlation analysis were used to study the spatiotemporal change of SPEI and its relationship with NDVI.

\section{Results and Discussion}

3.1. Interannual Variations of Drought at Different Time Scales in Xilingol. The sensitivity of the SPEI value at different time scales was obviously different as the time changes. The smaller the time scale, the more significant the change of wetness and dryness, and the value of SPEI would change greatly and even fluctuates between positive and negative. On the contrary, the larger the time scale, the more smooth the wet-dry rotation; there is only a number of continuous precipitation or no rain, high temperature, and so forth and it will make the change, which is reasonable to monitor longterm drought condition. According to Figure 2, SPEI shows a slight decrease trend at different time scales from 1961 to 2015. SPEI-1 fluctuates violently along the zero value, which fully reflects the frequent alternation of monthly drought and flood in Xilingol. The period of fluctuation of SPEI-3 and SPEI-6 is relatively long, reflecting the changing regularity of the wet-dry season. SPEI-12 was relatively stable and could reflect the interannual variation characteristics of drought. 

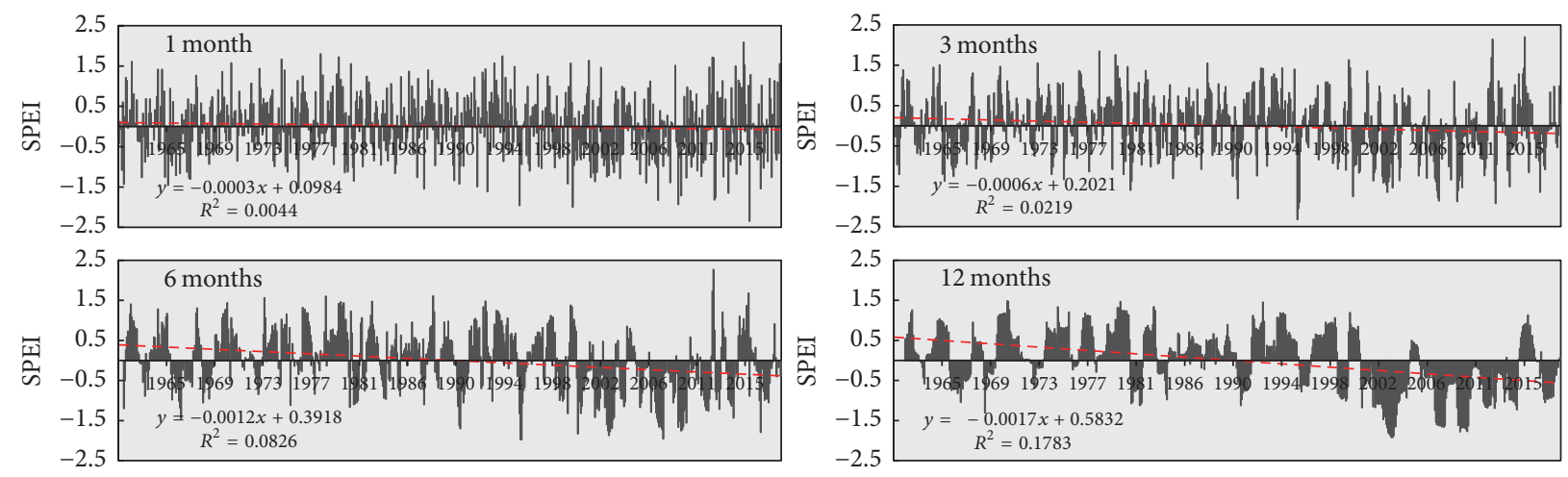

Figure 2: Time series of SPEI at 1-, 3-, 6-, and 12-month scales for period 1961-2015 of Xilingol.

TABLE 1: The standardized precipitation index (SPEI) categories based on the initial classification of SPEI values.

\begin{tabular}{lc}
\hline Categories & SPEI values \\
\hline Extreme drought & Less than -2.00 \\
Severe drought & -1.99 to -1.50 \\
Moderate drought & -1.49 to -1.00 \\
Light drought & -0.99 to -0.50 \\
Near normal & -0.49 to 0.50 \\
Humid & More than 0.50 \\
\hline
\end{tabular}

The situation of drought shown by SPEI-12 was similar to that of Xilingol in arid years in history, such as 1962, 1963, 1972 , 1980, 1989, 1994, 2000-2002, and 2005-2008, and the serious drought affected large area, reduction in grain yield, and the number of livestock; thus it caused great difficulties to farmers and herdsmen's life. Comparing with the drought severity classification table (Table 1), the drought frequency of SPEI decreased and the duration increased with the increase of time scale. In the period from 1961 to 1999 , the frequency of drought in Xilingol was low, and duration was short and the drought was less harmful. After 2000, the Xilingol region entered into the drought-frequent stage, and it lasted for a long time.

In order to further reveal the temporal variation of drought in Xilingol region, the Mann-Kendall, which is a nonparametric test method for testing the trend of time series allowing missing value and no need to prove the distribution of time series [25], was used to test 1961-2015 SPEI-12 sequence. The results are shown in Figure 3; the UF curve is the time series statistical curve and UB curve is the reverse time series statistical curve. When the significant level was 0.05, the UF and UB curves intersect in year 1997, and then the UF curve drops significantly and passes the significance level. The results showed that the drought in Xilingol region had obvious mutation change characteristics in interannual variation, and SPEI-12 decreased from 1997 showing trend of aridity.

3.2. Spatiotemporal Dynamics of SPEI and NDVI in Growing Season. Most of the vegetation in the Xilingol region stopped growing or was covered by snow in winter. In this paper the annual growing season from April to October was selected as the research period. In addition, due to the limited time series of MODIS data, 2000-2015 was chosen.

It can be seen from Figure 4(a) that the SPEI value of Xilingol region in the recent 16 years is probably in the range of -2 (2001) 1 (2012), and the rising rate is $0.0058 / \mathrm{yr}$. 2003 and 2012 are the humid period of Xilingol; 2001 and 2007 are the severe drought period. Figure 5 records the spatial distribution of drought in Xilingol from 2000 to 2015 of the growing season. The annual drought distribution in Xilingol region is shown clearly. Due to the uneven distribution of water and heat in the region, the degree of drought is not the same each year, so a larger area of drought appeared in 2000, 2001, 2005, and 2007. The spatial variation of SPEI showed an increasing tendency in the whole growing season in Xilingol area, $40 \%$ of which increased significantly, mainly in the eastern meadow steppe of the study area (Figure 6(a)).

In the recent 16 years, the average NDVI in Xilingol steppe showed an upward trend with an increasing rate of $0.0021 / \mathrm{yr}$ (Figure 4(b)), which was in accordance with the general improvement of Xilingol grassland vegetation in recent years [26]. For example, NDVI in 2003 and 2012 correspond to the peak of SPEI, while the NDVI trough in 2001 and 2007 corresponds to the SPEI trough of same year. And the NDVI in $81.53 \%$ of the region increased specially (Figure 6(b)), which was consistent with the increase of SPEI, indicating that drought was the main factor affecting the growth of Xilingol grassland vegetation.

\subsection{Drought Impact on Vegetation NDVI in Xilingol. Accord-} ing to the above analysis, between 2000 and 2015, the SPEI and NDVI in Xilingol region are highly consistent with the change of time series, and the vegetation growth is relatively good in humid years. Through the Pearson correlation analysis, we can see that in the annual growing season SPEI and NDVI are significantly positively correlated $(r=0.905$, $P<0.01$ ). Figure 6(c) shows the results of pixel-by-pixel correlation analysis of SPEI and NDVI. The results showed that the area of positive correlation between SPEI and NDVI in the growing season was much larger than that of negative correlation area, and the positive correlation area was $98.42 \%$ 


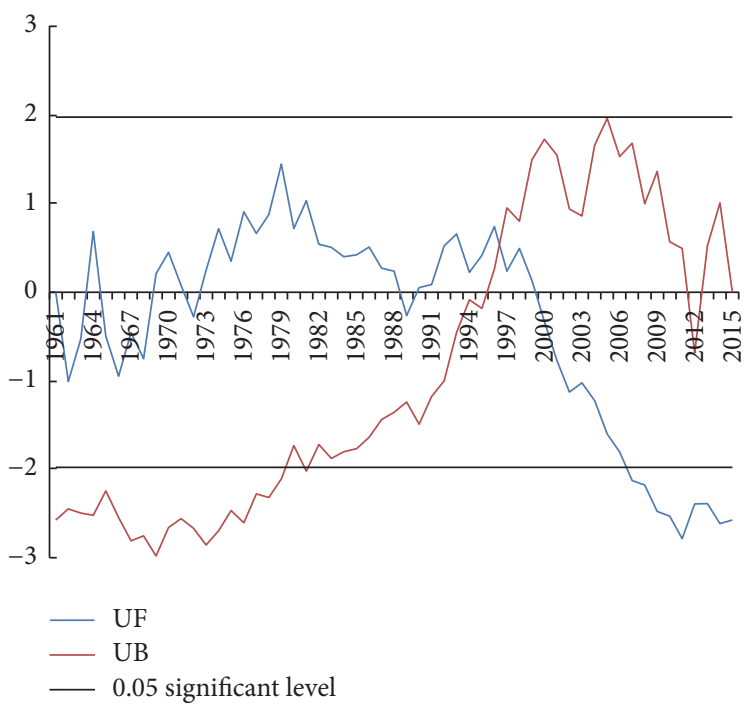

Figure 3: Mann-Kendall test for annual SPEI-12 series in Xilingol from 1961 to 2015.

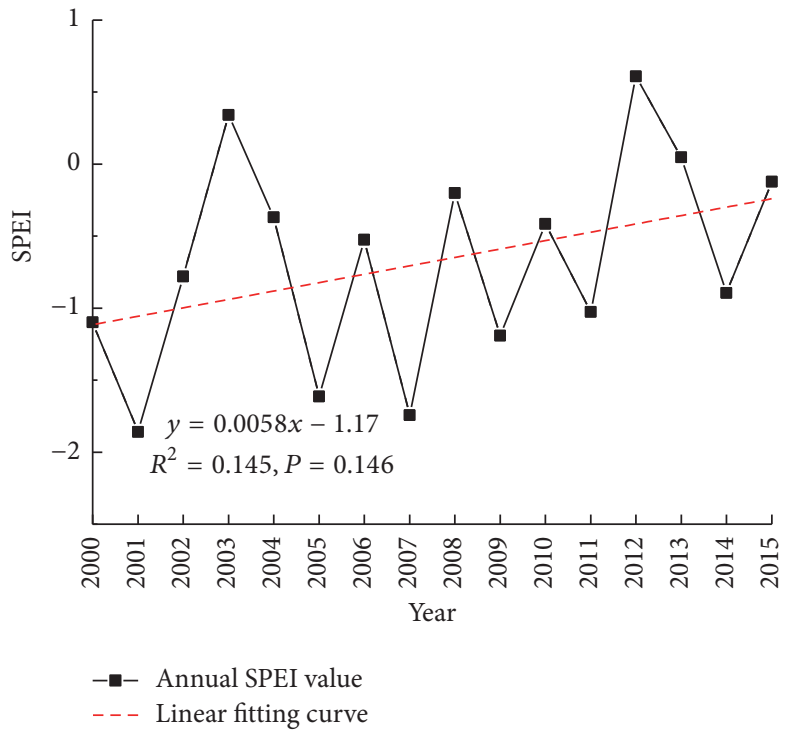

(a)

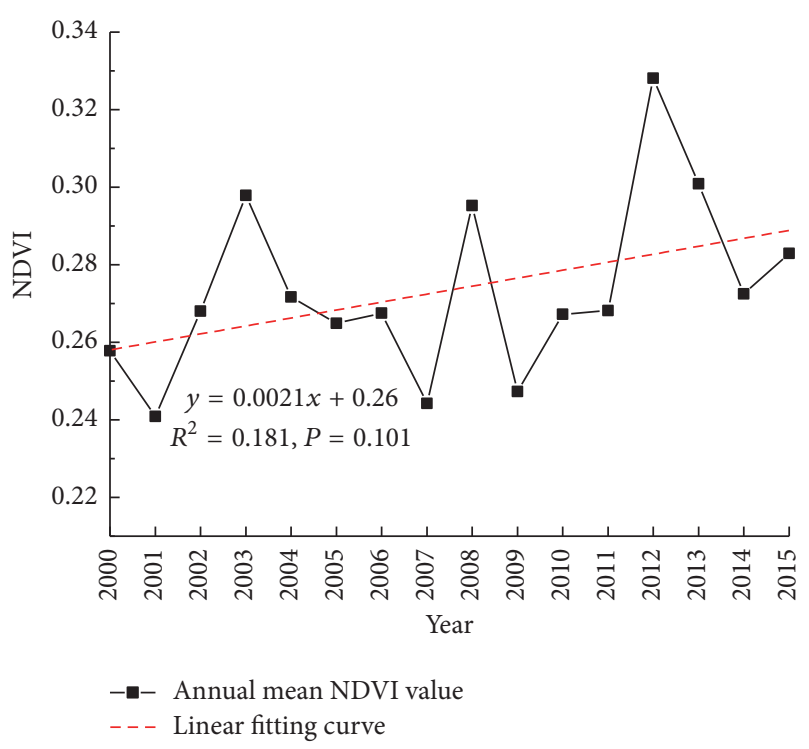

(b)

FIGURE 4: Interannual variations of SPEI (a) and NDVI (b) in Xilingol during 2000-2015.

of the total area of the study area. Among them, $24.32 \%$ has no significant positive correlation, mainly in the Dongwuqi and eastern and southern grassland desert in Xiwuqi and northern Sunitezuoqi. It can be seen from Table 2 that whole of Xilingol and its four grassland types have a significant positive response to drought at different time scales. The correlation coefficient was the largest for desert steppe at the 3-month time scale, while for other types the correlation coefficients were the highest at the 6-month time scale. And except for the steppe desert, the correlation coefficients were the lowest at the 12-month time scale, indicating that Xilingol grassland has a strong response to the short-term (SPEI-1), seasonal (SPEI-3), and medium-term (SPEI-6) drought and a lower response to long-term (SPEI-12) drought.
TABLE 2: Pearson correlation coefficients between SPEI and NDVI at different time scales.

\begin{tabular}{lcccc}
\hline & SPEI-1 & SPEI-3 & SPEI-6 & SPEI-12 \\
\hline Xilingol & 0.72 & 0.76 & 0.83 & 0.64 \\
Meadow steppe & 0.48 & 0.53 & 0.64 & 0.53 \\
Typical steppe & 0.69 & 0.73 & 0.79 & 0.61 \\
Steppe desert & 0.62 & 0.65 & 0.79 & 0.71 \\
Desert steppe & 0.66 & 0.69 & 0.65 & 0.44 \\
\hline
\end{tabular}

The above analysis shows that drought has vital impact on the annual NDVI. However, the effect of drought on monthly NDVI was variable [27]. In order to examine the drought 


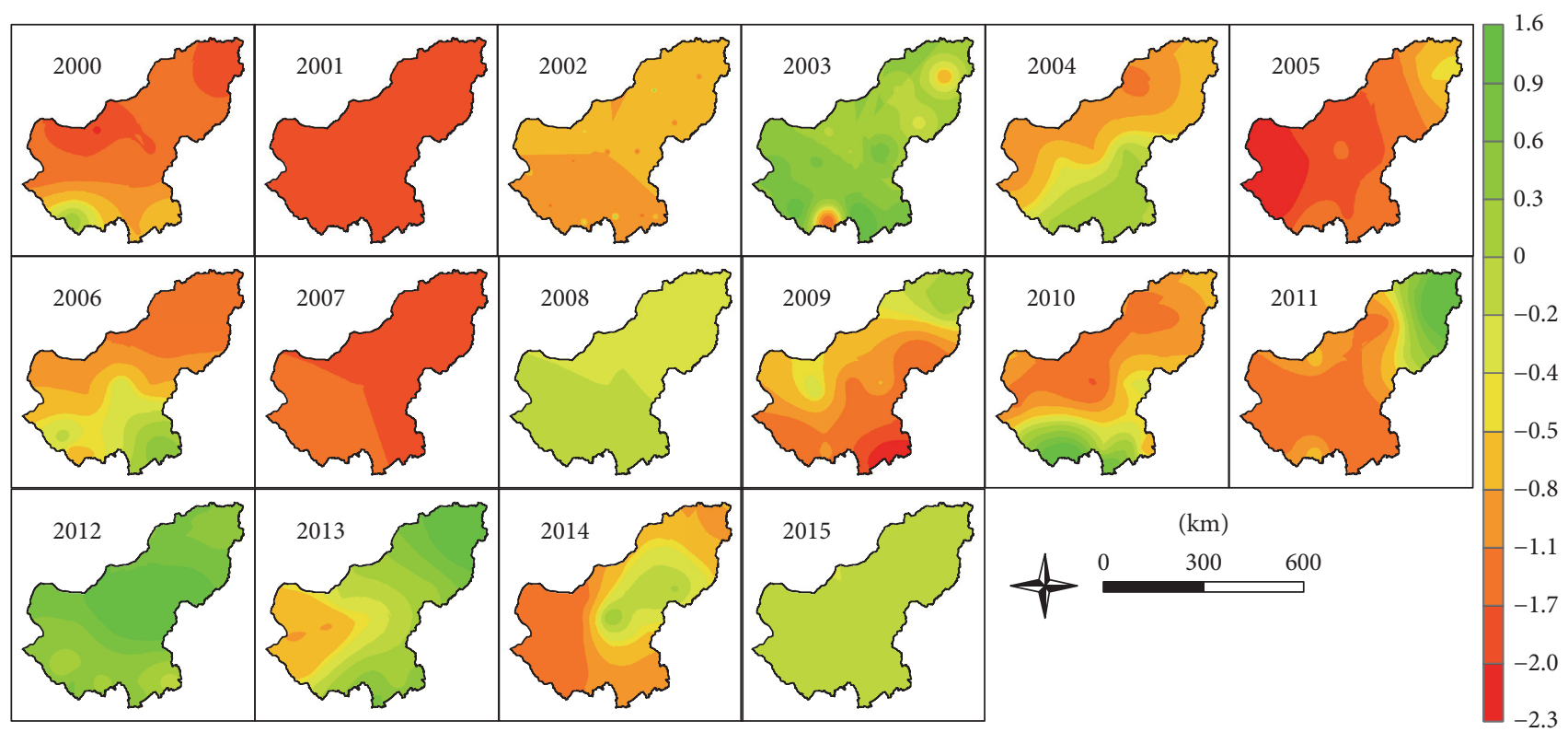

FIGURE 5: Spatial distribution of drought in Xilingol during 2000-2015.

TABle 3: Pearson correlation coefficient of NDVI and SPEI in Xilingol at different time scales.

\begin{tabular}{|c|c|c|c|c|}
\hline \multirow{2}{*}{ NDVI } & \multicolumn{4}{|c|}{ SPEI } \\
\hline & 0 month & 1 month & 2 months & 3 months \\
\hline April & -0.411 & 0.184 & 0.051 & -0.362 \\
\hline May & 0.204 & 0.408 & 0.044 & 0.288 \\
\hline June & $0.576^{*}$ & 0.182 & 0.102 & 0.224 \\
\hline July & $0.708^{* *}$ & $0.730^{* *}$ & 0.001 & -0.102 \\
\hline August & 0.078 & $0.808^{* *}$ & 0.481 & -0.4 \\
\hline September & 0.34 & 0.457 & $0.681^{* *}$ & $0.626^{* *}$ \\
\hline October & 0.004 & 0.488 & 0.303 & $0.717^{* *}$ \\
\hline
\end{tabular}

Significant at ${ }^{*} a=0.05$ and ${ }^{* *} a=0.01$ levels.

impact on the monthly NDVI, we choose the humid years 2003 and 2012 and dry years 2001 and 2007 to investigate the dynamics of SPEI and NDVI of each month in growing season. It can be seen from Figure 7 that the vegetation in Xilingol was the best in the July and August, while the drought is severe in July and August. The possible reason for this phenomenon is that the precipitation in Xilingol region is abundant in July and August, and the temperature is the highest. The summer vegetation in this area is mainly controlled by precipitation, and the high temperature will accelerate the evaporation and lead to the drought intensification [28]. In the wet years 2003 and 2012, the NDVI and SPEI curves of the growing season were above the mean NDVI and the multiyear average SPEI curves. In 2003, NDVI reached the highest value in July; SPEI was higher in May and June; in 2012, NDVI reached the highest value in August; SPEI value was higher in June and July. In the dry years 2001 and 2007, the NDVI and SPEI curves were below the multiyear averaged NDVI and SPEI curves. In 2001, NDVI reached the highest value in July, and SPEI was higher in July and August, indicating that the effect of drought on vegetation is lagging. And there was moderate drought in April 2007, but it did not have a negative impact on the vegetation in April, indicating that drought had little effect on green up.

In order to study the lag effect of drought on vegetation, we selected 0 month, 1 month, 2 months, and 3 months scale to analyze the correlation between SPEI and NDVI by Pearson correlation analysis. The results are shown in Table 3; we found in April and May that NDVI and SPEI showed a weak positive correlation; 4-5 months is Xilingol grassland's returning green period, indicating that the drought in the Xilingol grassland turning green has little effect. There was a significant positive correlation between NDVI and 0 month SPEI in June and NDVI in July and SPEI in 0 month and 1 month in July and a significant positive correlation between NDVI and 0 month SPEI in June and 1 month in August, indicating that the drought in the month and the previous month grassland growth play an extremely 


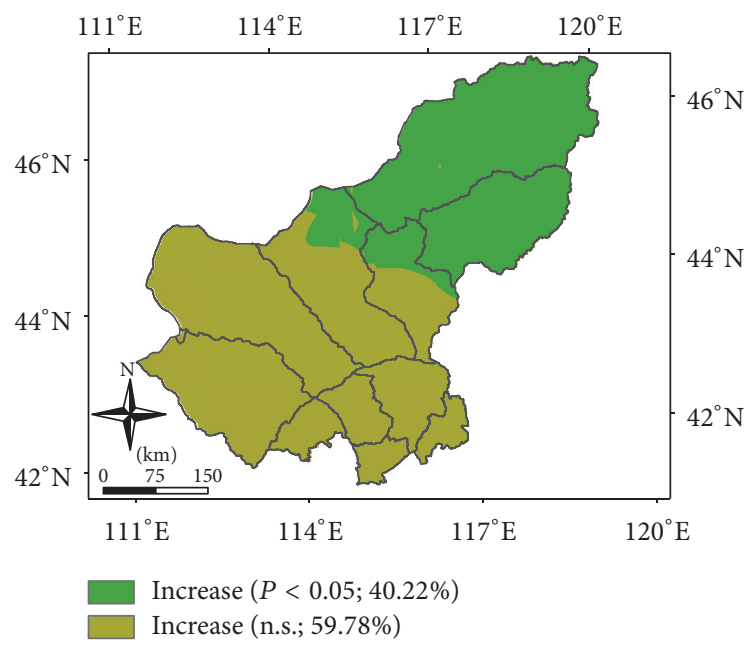

(a)

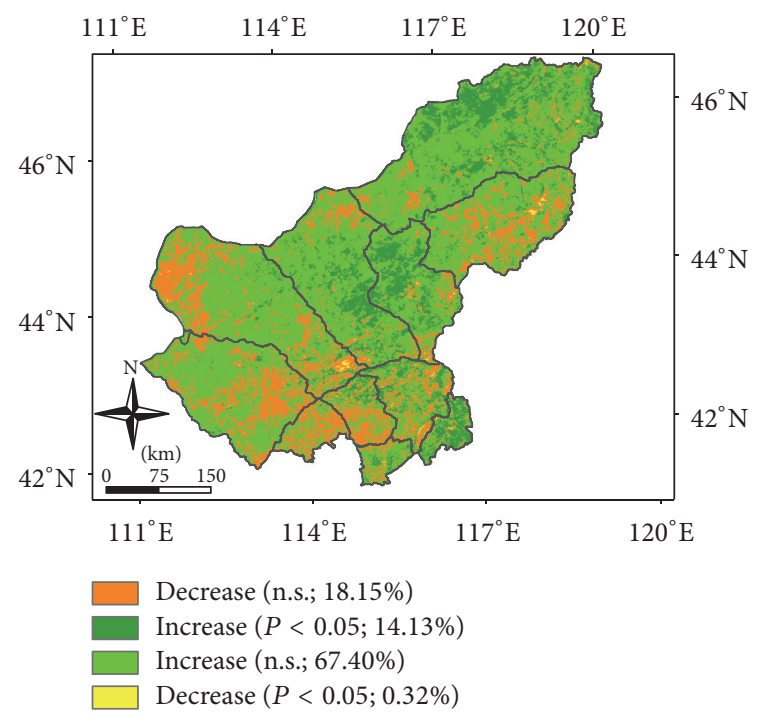

(b)

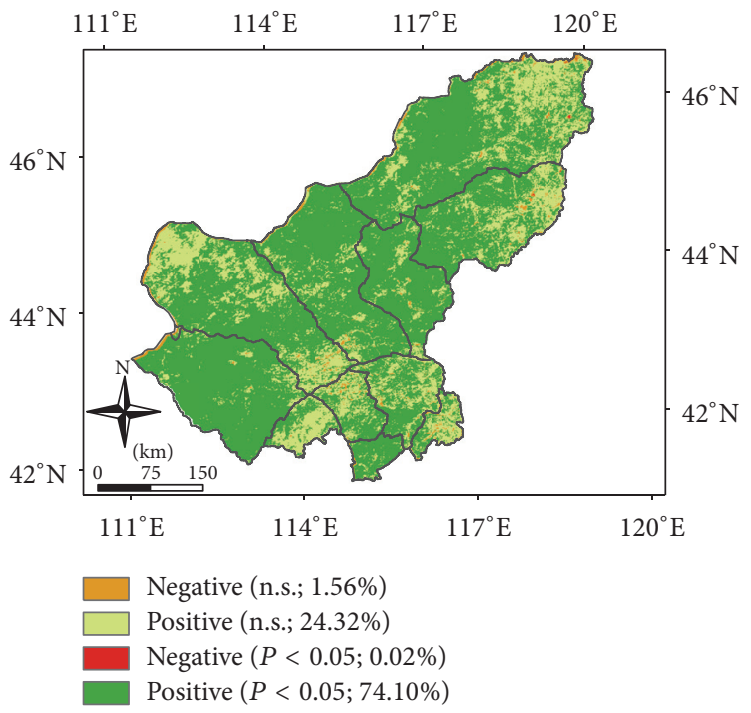

(c)

Figure 6: Spatial pattern of SPEI (a), NDVI (b) trend, and their correlation (c) during 2000-2015.

important role. During September to October, NDVI had a significant positive response to SPEI of 2 months and 3 months and a strong response to short-term drought.

3.4. Changes of Vegetation in Different Grassland Types and Their Response to Drought. Different grassland types in Xilingol region have different responses to drought due to their own physiological and ecological characteristics and geographical differences. Figure 8 shows the change trend of SPEI and NDVI of different grassland types during 2000 to 2015, with different degrees of rising trend. And the SPEI values stayed the same, decreasing in the order of meadow steppe $>$ steppe desert $>$ typical steppe $>$ desert steppe, with the mean values of $-0.510,-0.635,-0.672$, and -0.814 , respectively. In addition to natural conditions, the steppe desertification is mainly affected by human activities.
That is to say, grassland types are gradually transformed by artificial transformation such as planting trees and grasses. The diversity of shrub communities is relatively abundant, and the coverage was also relatively high [29]. This may be the reason why the steppe desert NDVI is slightly higher than typical steppe in the study area, but the gap is not obvious.

Figure 9 shows the response characteristics of different grassland types to different scales of drought. The correlation coefficients of NDVI and SPEI index of meadow steppe are shown in Figure 9(a). It showed that there is no significant correlation between the NDVI and SPEI index of meadow steppe in April, and the correlation between NDVI and drought index in May was significantly higher than that in April. The reason is that most of the meadow steppe turned green in May and small part of them became green in late April, so the meadow steppe in April had no obvious response 

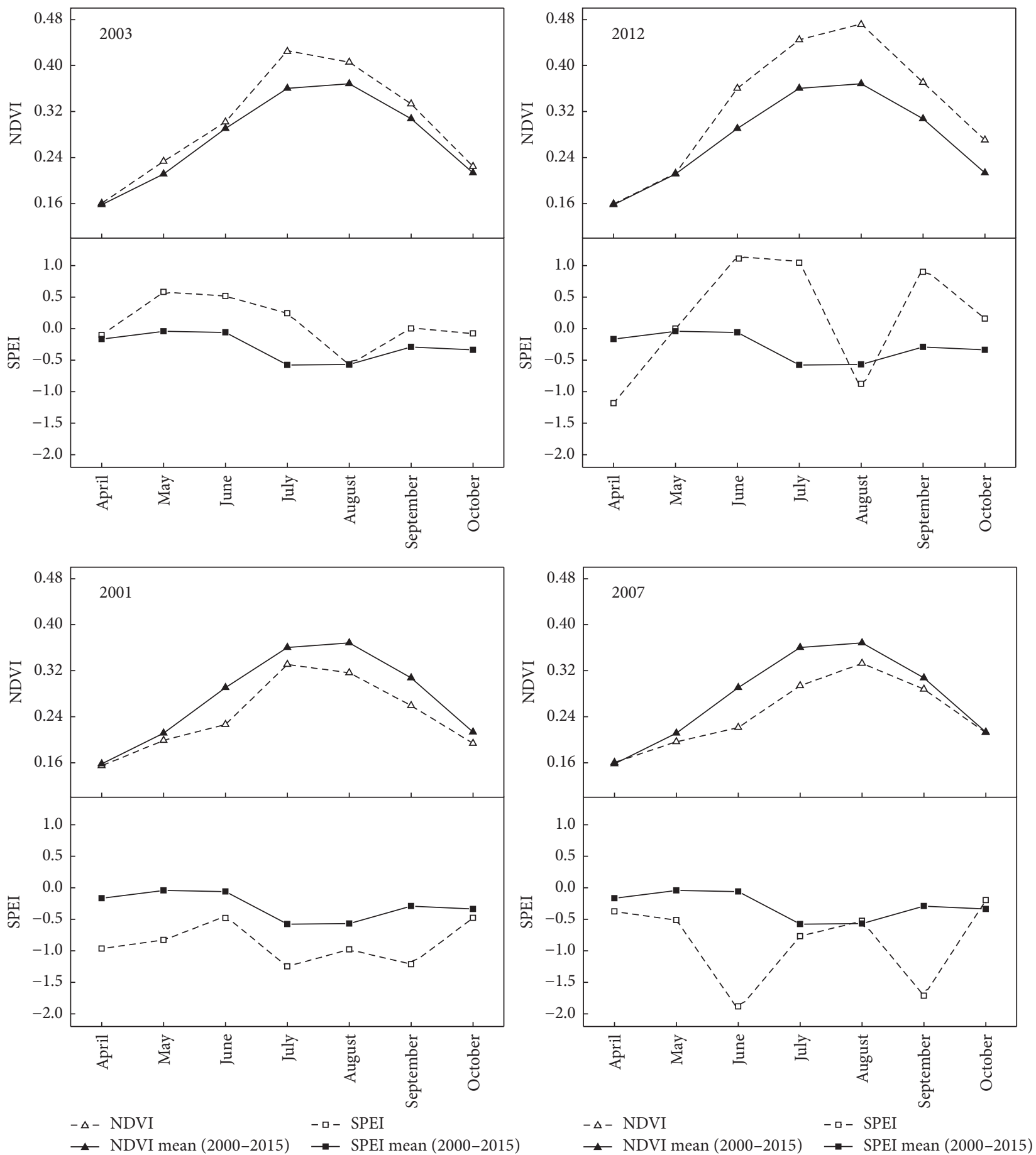

FIGURE 7: Monthly variations in mean NDVI and SPEI in growing season (April to October) of 2001, 2003, 2007, and 2012 and the 2000-2015 average in Xilingol. The dashed and solid lines denote the 16 years' mean and monthly NDVI or SPEI, respectively.

to the climate drought. And, in May, the steppe began to develop and the steppe turned into the growing season, the drought response gradually increased. In June, the NDVI of meadow steppe showed strong correlation with SPEI of 0 month, and NDVI of steppe was more sensitive to drought. NDVI in July and 1 month, NDVI in August and 2 months, and NDVI in September and 3 months showed a significant positive correlation indicating that these three months of vegetation had a positive response to drought in the earlier period and the effect of drought on vegetation had lagged. In October, the correlation between NDVI and SPEI in meadow steppe was weak, which indicated that the response to climate drought was not obvious. When entering October, the steppe vegetation entered the period of yellowing and the 

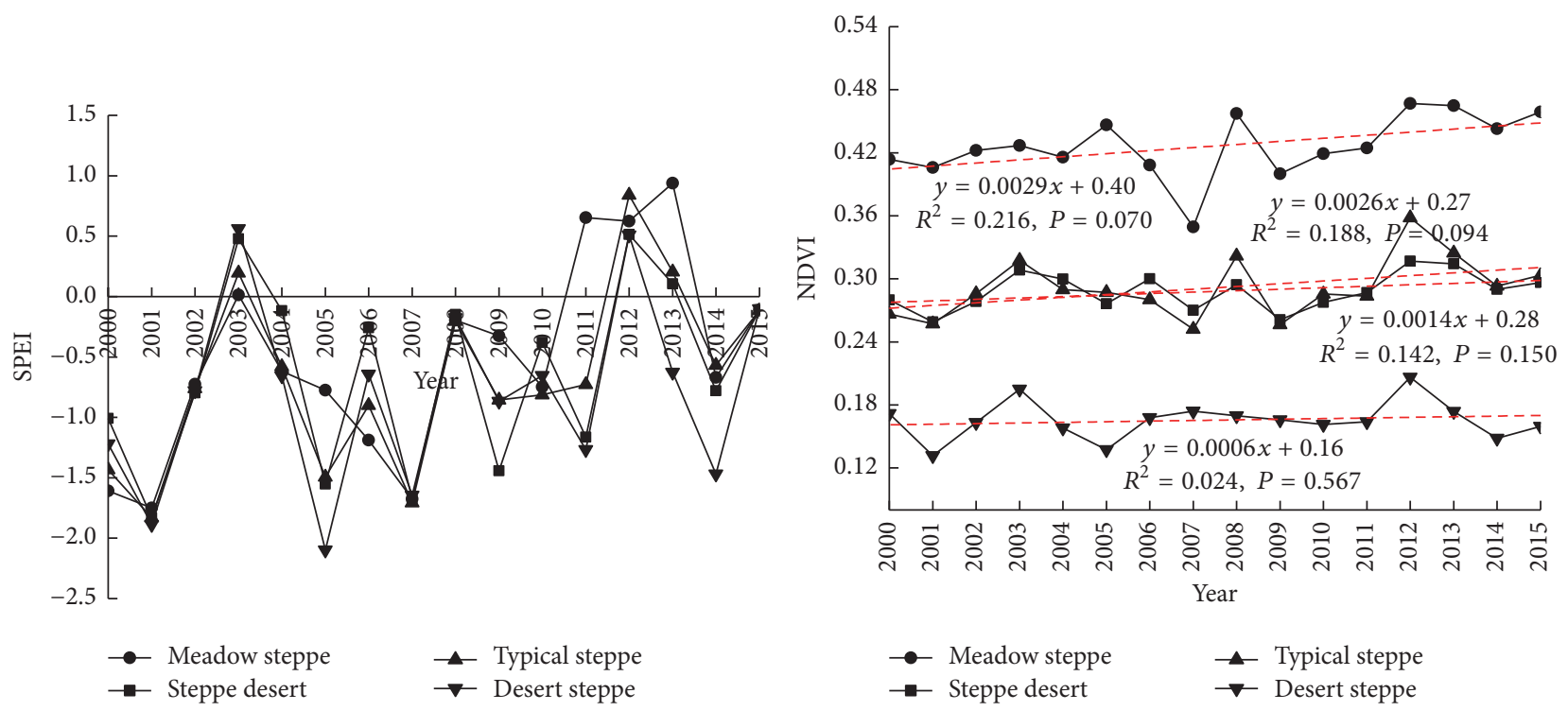

FIGURE 8: Interannual variations of NDVI and SPEI in four grassland types of Xilingol during 2000-2015.

temperature decreased, which led to the decrease of grassland green rate.

According to the correlation analysis between time series of NDVI and SPEI of typical steppe, the results are shown in Figure 9(b). Compared with meadow steppe, the NDVI of typical steppe was highly correlated with SPEI at different time scales, indicating that the response of typical steppe to drought was more obvious than that of meadow steppe. The correlation between grassland NDVI and SPEI was not significant at the early stage of typical grassland growth, which indicated that grassland turning green period had less response to drought at these different time scales. During June to August, the grassland NDVI had a significant positive response to the drought in the same month and in the early period. After entering September, the grassland began to wither short-term drought on the typical steppe to a certain extent.

The correlation of time series between NDVI and SPEI of steppe desert is shown in Figure 9(c). It can be seen that the correlation coefficient of steppe desert NDVI and SPEI change temporally, which indicates that the response of steppe desert to drought climate at different time scales is very different. The correlation between NDVI and SPEI at different time scales in April was greater, indicating that drought had a greater impact on the greening of steppe desert. The response of NDVI to drought was similar to that of desert steppe (Figure 9(d)) in other months. The correlation between NDVI and SPEI at different time scales was not as obvious as in other types of steppe. In general, the response of SPEI in different grassland types in Xilingol grassland was not significant in the early of the growing season, and JuneAugust NDVI respond to 0 month and 1 month SPEI strongly, In October, grassland withering period, NDVI was sensitive to 3-month SPEI.

\section{Conclusions}

In this study, we explore the spatial and temporal dynamics of SPEI and NDVI over the Xilingol grassland and investigate the impact of drought on the NDVI in Xilingol grassland during the growing season (April-October). The main conclusions include the following:

(1) There is an increasing trend of annual drought in Xilingol during 1961-2015, and it has a mutation in 1997 and the drought becomes more intense after this year.

(2) In the recent 16 years, the annual growing season SPEI has an obvious upward trend in time and the apparent wetting spatially. Correspondingly, the growing season NDVI showed upward trend.

(3) Vegetation coverage in Xilingol grew better in humid years and opposite in arid years. SPEI and NDVI had a significant positive correlation $(r=0.905, P<0.01)$; $98 \%$ of the region showed positive correlation, indicating that meteorological drought affects vegetation growth more in arid and semiarid region.

(4) Xilingol grassland has a strong response to the shortterm, seasonal, and medium-term drought and a lower response to long-term drought. And the effect of drought on vegetation has lag effect, and the responses of different grassland types to different scales of drought were different.

\section{Competing Interests}

The authors declare that there is no conflict of interests regarding the publication of this paper. 


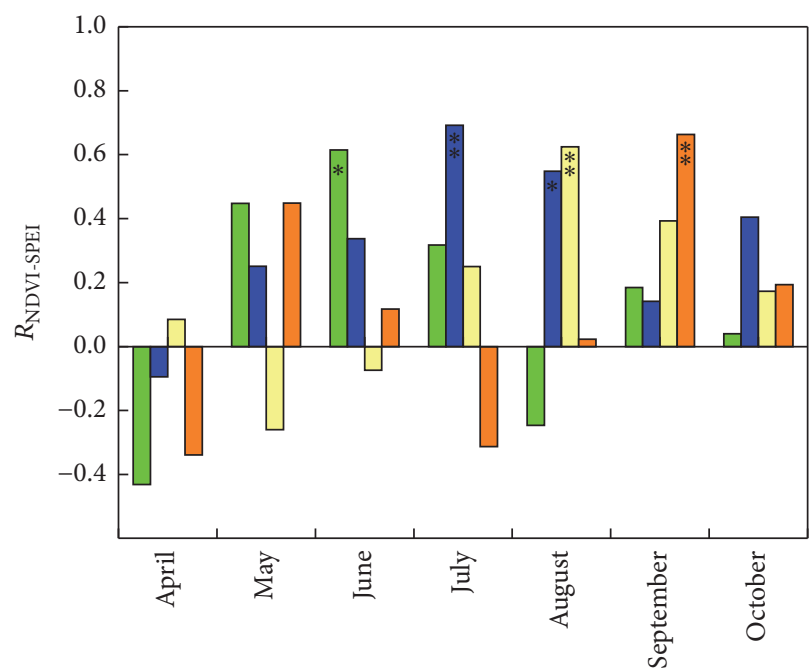

Month

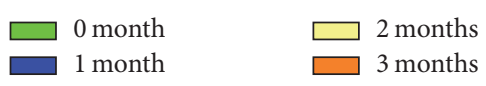

(a) Meadow steppe

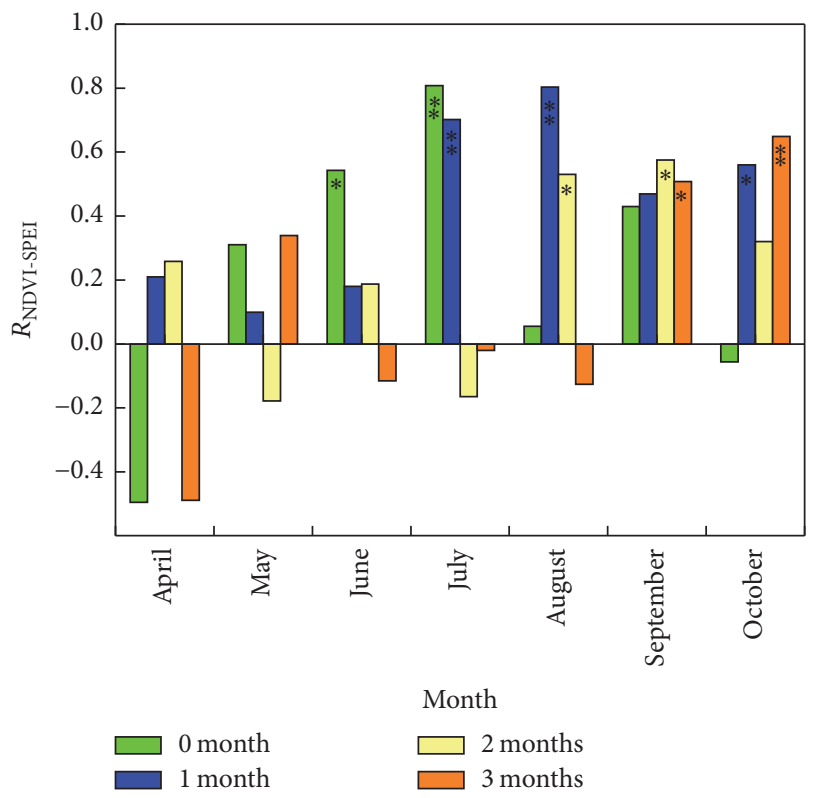

(c) Steppe desert

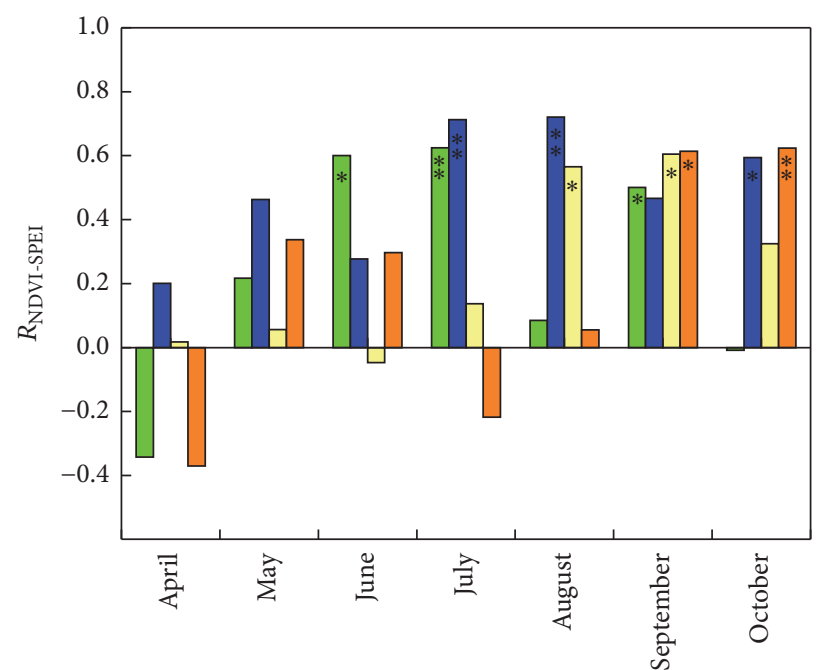

Month

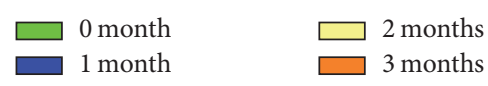

(b) Typical steppe

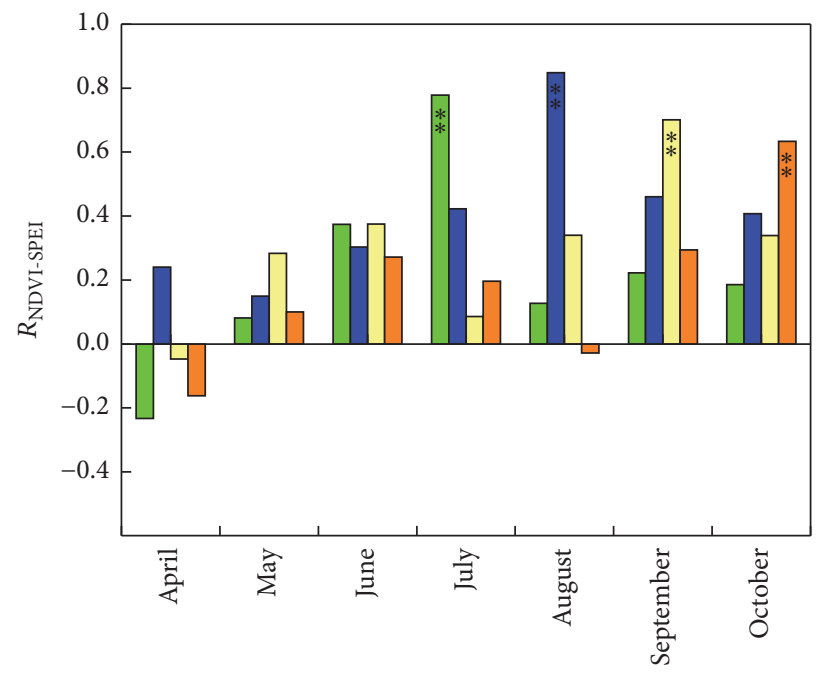

Month

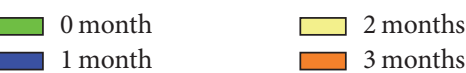

(d) Desert steppe

FIGURE 9: Pearson correlation coefficient of NDVI and SPEI in four grasslands at different timescales (the horizontal axis was the months, and the vertical axis was the correlation coefficient between SPEI and NDVI). $*$ is 0.1 significance level and $* *$ is 0.05 significance level.

\section{Acknowledgments}

This study was supported by the national "12th-five" Science and Technology Support Projects of China (Grants nos. 2013BAK05B01 and 2013BAK05B02).

\section{References}

[1] D. S. Ojima, B. O. M. Dirks, E. P. Glenn, C. E. Owensby, and J. O. Scurlock, "Assessment of C budget for grasslands and drylands of the world," Water, Air, and Soil Pollution, vol. 70, no. 1, pp. 95-109, 1993.

[2] G. X. Liu, "Current situation of monitoring, assessment, problems and countermeasures of grassland eco-environmental quality," Chinese Journal of Grassland, vol. 31, no. 3, pp. 8-12, 2009.

[3] Y. L. Wang, W. L. Yun, W. Wang, and Q. Hou, "Effect of climate warming on spatial pattern and temporal change of precipitation in typical steppe," Journal of Arid Land Resources and Environment, vol. 23, no. 1, pp. 82-85, 2009. 
[4] H. Xiang-Zhong, H. Yan-Bin, W. Yan-Fen, Z. Xiao- Qi, H. Xi, and H. Jun-Jie, "Impact of extreme drought on net ecosystem exchange from lemus chinensis steppe in xilin river basin, china," Chinese Journal of Plant Ecology, vol. 30, no. 6, pp. 894900, 2006.

[5] S. Piao, A. Mohammat, J. Fang, Q. Cai, and J. Feng, "NDVIbased increase in growth of temperate grasslands and its responses to climate changes in China," Global Environmental Change, vol. 16, no. 4, pp. 340-348, 2006.

[6] S. L. Piao, J. Y. Fang, J. S. He, and X. Xiao, "Spatial distribution of grassland biomass in China," Acta Phytocecologica Sinica, vol. 28, no. 4, pp. 491-498, 2004.

[7] S. L. Liu, Y. Y. Tian, Y. J. Yin, N. N. An, and S. K. Dong, “Temporal dynamics of vegetation NDVI and its response to drought conditions in Yunnan Province," Acta Ecologica Sinica, vol. 36, no. 15, pp. 4699-4707, 2016.

[8] S. Beguería, S. M. Vicente-Serrano, and M. Angulo-Martínez, "A multiscalar global drought dataset: The SPEI base: a new gridded product for the analysis of drought variability and impacts," Bulletin of the American Meteorological Society, vol. 91, no. 10, pp. 1351-1356, 2010.

[9] A. S. Goudie and N. J. Middleton, "The changing frequency of dust storms through time," Climatic Change, vol. 20, no. 3, pp. 197-225, 1992.

[10] S. D. Schubert, M. J. Suarez, P. J. Pegion, R. D. Koster, and J. T. Bacmeister, "On the cause of the 1930s dust bowl," Science, vol. 303, no. 5665, pp. 1855-1859, 2004.

[11] H. Wang, X.-B. Li, X. Li, and D.-D. Wang, "Grassland response to drought in northern China," Shengtai Xuebao/ Acta Ecologica Sinica, vol. 28, no. 1, pp. 172-182, 2008.

[12] A. K. Mishra and V. P. Singh, "A review of drought concepts," Journal of Hydrology, vol. 391, no. 1-2, pp. 202-216, 2010.

[13] S. M. Vicente-Serrano, S. Beguería, and J. I. López-Moreno, "A multiscalar drought index sensitive to global warming: the standardized precipitation evapotranspiration index," Journal of Climate, vol. 23, no. 7, pp. 1696-1718, 2010.

[14] L. G. Cao, P. X. Liu, K. X. Zhang, and H. Y. Wang, "Analysis on response of grasslands to climate change and its spatial difference in Xilingol League," Arid Zone Research, vol. 28, no. 5, pp. 789-794, 2011.

[15] C. Chen, J. Wang, X. B. Pan, Z. H. Pan, and Y. R. Wei, "Simulation study regarding the impact of climate change on grass productivity in Inner Mongolia," Acta Agrestia Sinica, vol. 21, no. 5, pp. 850-860, 2013.

[16] Z. H. Gu, J. Chen, P. J. Shi, and M. Xu, "Correlation analysis of NDVI difference series and climate variables in Xilingole steppe from 1983 to 1999," Acta Phytoecologica Sinica, vol. 29, no. 5, pp. 753-765, 2005.

[17] H. Bagan, Q. Wang, Y. Yang, Y. Yasuoka, and Y. Bao, "Land cover classification using moderate resolution imaging spectrometerenhanced vegetation index time-series data and self-organizing map neural network in Inner Mongolia, China," Journal of Applied Remote Sensing, vol. 1, no. 1, pp. 157-167, 2007.

[18] Z. H. Li, Y. J. Bao, H. M. Wang, T. Xu, Y. Cheng, and J. X. Gao, "The analysis on degeneration status and the driving force of Xilinguole steppe," Ecology and Environment, vol. 17, no. 6, pp. 2312-2318, 2008.

[19] Y. L. Gong, H. F. Zhang, and X. Xiao, "3S Based disaster relief of drought disaster in Xilingol League," Journal of Catastrophology, vol. 24, no. 2, pp. 123-127, 2009.
[20] J. W. Wu, J. R. Li, T. Sun, F. Li, and X. S. Zhou, "Risk assessment on climatic factors resulting in sandstorm disasters in Xilingol region," Arid Zone Research, vol. 28, no. 6, pp. 936-943, 2011.

[21] R. Zhang, H. Zou, M. Hong, A. Zhou, and G. Zeng, "Risk analysis of water resources crisis in the Lancang-Mekong river drainage basin under the background of climate change," Journal of Risk Analysis and Crisis Response, vol. 2, no. 3, pp. 209-213, 2012.

[22] B. N. Holben, "Characteristics of maximum-value composite images from temporal AVHRR data," International Journal of Remote Sensing, vol. 7, no. 11, pp. 1417-1434, 1986.

[23] Y. L. Hang, G. Bao, Y. H. Bao, Burenjirigala, and D. Altantuya, "Spatiotemporal changes of vegetation coverage in Xilin Gol grassland and its responses to climate change during 20002010," Acta Agrestia Sinica, vol. 22, no. 6, pp. 1194-1204, 2014.

[24] C. W. Thornthwaite, "An approach toward a rational classification of climate," Geographical Review, vol. 38, no. 1, pp. 55-94, 1948.

[25] Z. Ma and C. Fu, "Some evidence of drying trend over northern China from 1951 to 2004," Chinese Science Bulletin, vol. 51, no. 23, pp. 2913-2925, 2006.

[26] Y. Yan, A. Tengtuya, Y. Hu, Y. Liu, and G. Yu, “The tendency and its spatial pattern of grassland changes in the east xilin gol from 1975 to 2009," Geo-information Science, vol. 13, no. 4, pp. 549-555, 2011.

[27] R. Trigo, C. M. Gouveia, S. Begueria, and S. Vicente-Serrano, "Drought impacts on vegetation dynamics in the Mediterranean based on remote sensing and multi-scale drought indices," Keio-IES Discussion Paper Series 17, 2014.

[28] L. Zhou, C. J. Tucker, R. K. Kaufmann, D. Slayback, N. V. Shabanov, and R. B. Myneni, "Variations in northern vegetation activity inferred from satellite data of vegetation index during 1981 to 1999," Journal of Geophysical Research Atmospheres, vol. 106, no. 17, pp. 20069-20083, 2001.

[29] X. Li and X. Zhang, "Biodiversity of shrub community in desert steppe and steppe desert on Erdos plateau," Chinese Journal of Applied Ecology, vol. 10, no. 6, pp. 665-669, 1999. 


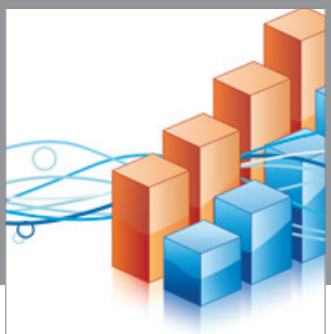

Advances in

Operations Research

vatem alat4

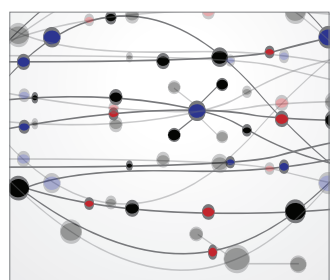

\section{The Scientific} World Journal
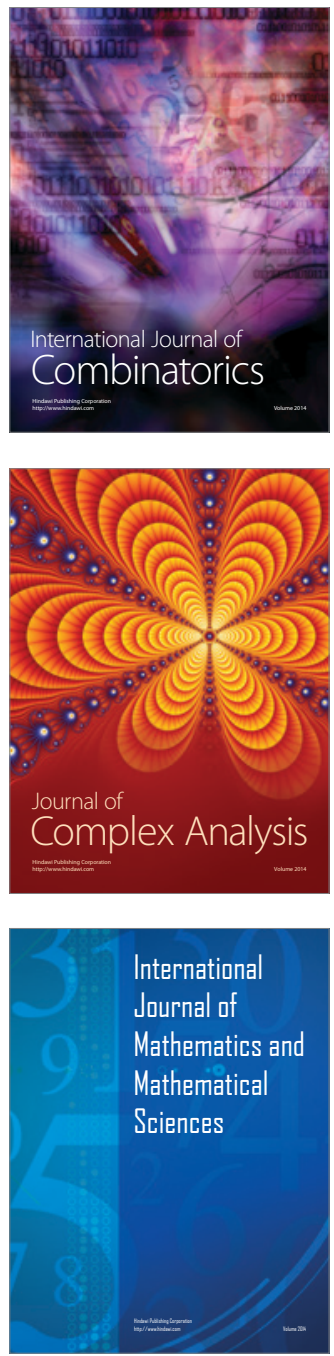
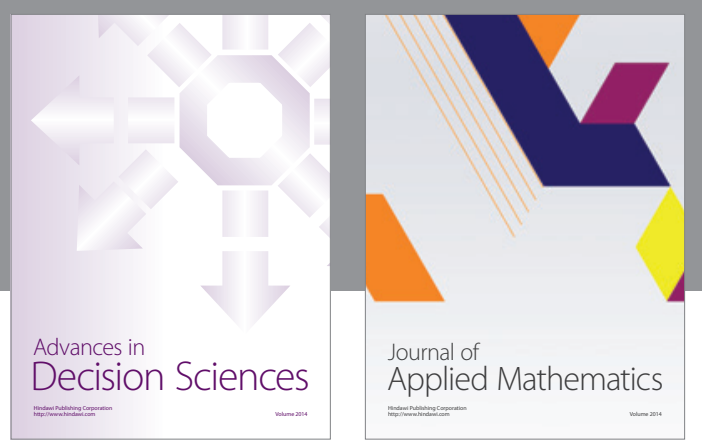

Algebra

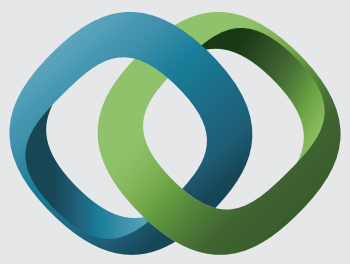

\section{Hindawi}

Submit your manuscripts at

https://www.hindawi.com
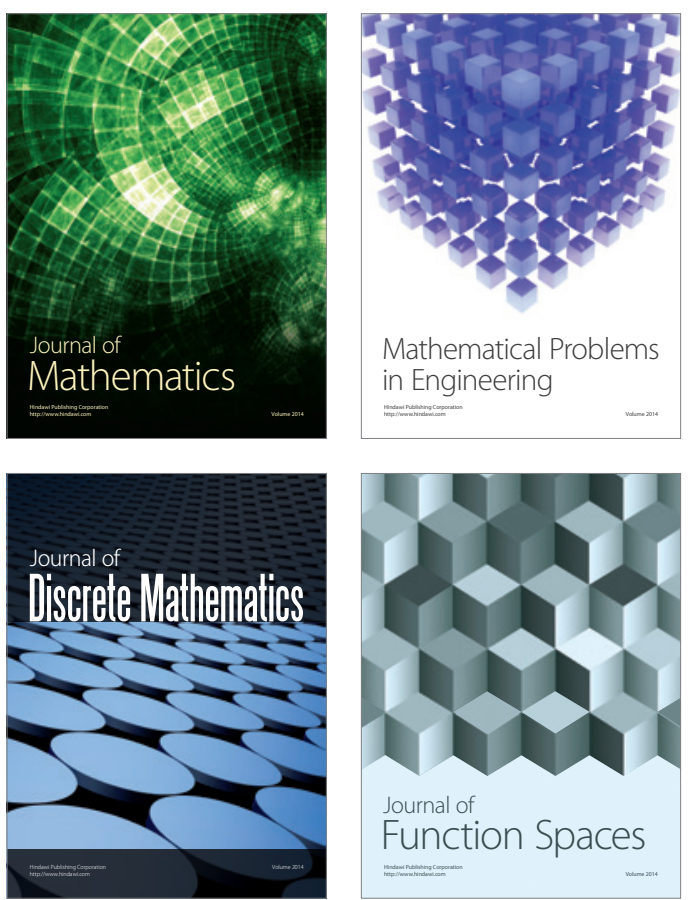

Mathematical Problems in Engineering
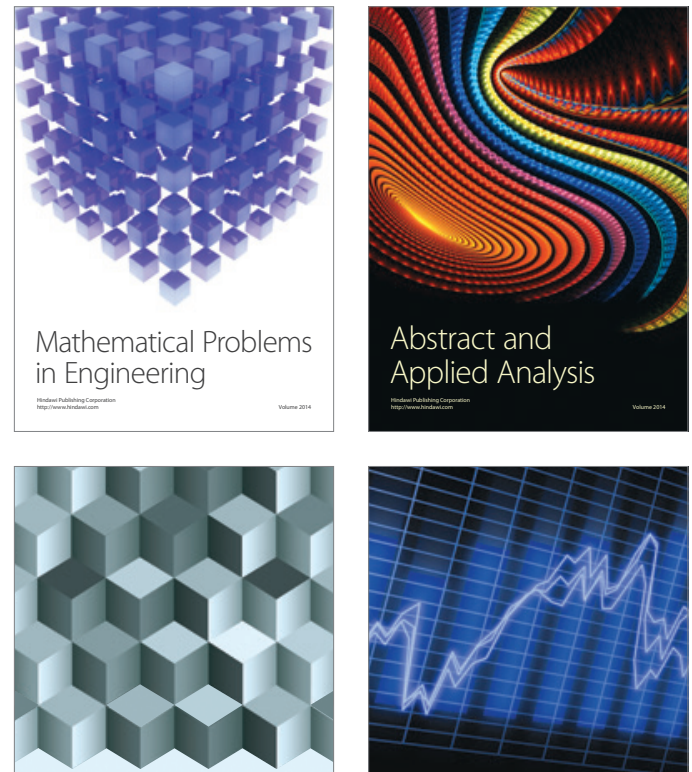

Journal of

Function Spaces

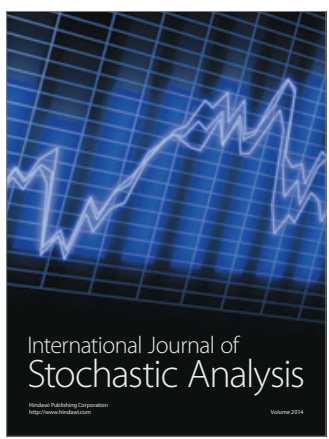

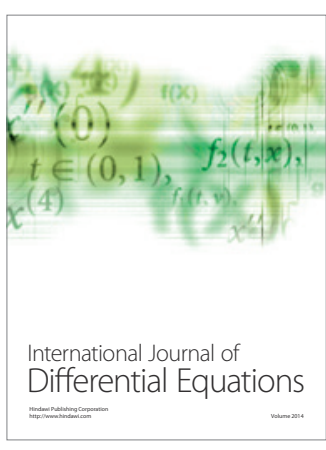
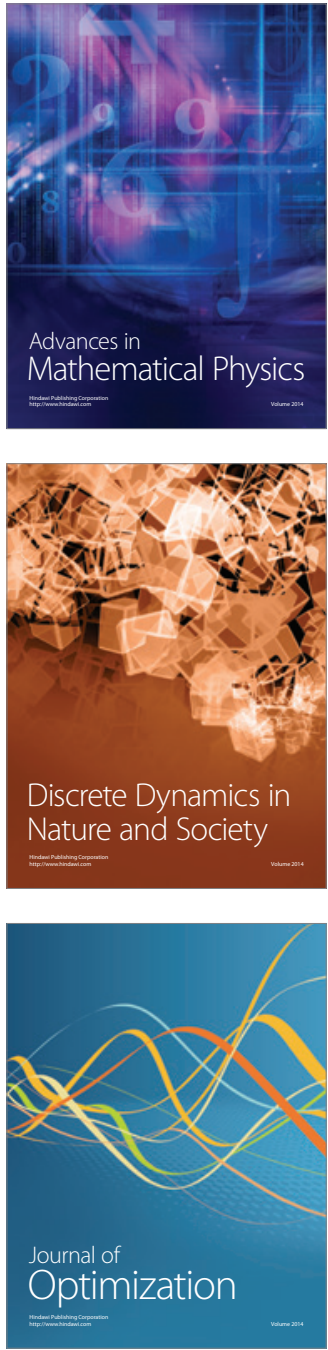